Replication

\title{
Firm valuation from customer equity: When does it work and when does it fail?
}

\author{
Shoutong Thomas Zhang* \\ London Business School, Sussex Place, London NW1 4SA, United Kingdom
}

\section{A R T I C L E I N F O}

\section{Article history:}

First received on August 3, 2015

and was under review for 4 months

Available online $\mathrm{xxxx}$

Replication Editor: Joel C. Huber

\section{Keywords:}

Customer lifetime value

Customer equity

Innovation

\begin{abstract}
A B S T R A C T
Is customer equity a good proxy for a firm's market value? Using data from Netflix over 10 years, I provide evidence that a CLV-based customer equity model tracks market capitalization remarkably well under versatile conditions of stable growth, profit volatility, and even a broad market crash. However, if a firm shifts business model through radical innovation, the customer equity model requires recalibration to continue tracking market capitalization.
\end{abstract}

(c) 2016 Elsevier B.V. All rights reserved.

\section{Introduction}

Customer lifetime value (CLV) - the present value of a customer's future benefits to a firm - has been extensively publicized as a crucial marketing metric to create firm value (Fader, 2012; Gupta \& Lehmann, 2005). A major empirical foundation for its validity rests on Gupta, Lehmann, and Stuart (2004), which showed the feasibility of using a firm's customer equity - the sum of CLVs over all customers - to derive a firm's stock market capitalization.

A key proposed feature of customer equity as a proxy for market capitalization is its suitability over all phases of a firm's lifecycle, notably in periods of high growth or negative earnings, when traditional financial valuation models of the firm are harder to apply (Gupta et al., 2004).

However, companies rarely report customer metrics over long enough time for a within-firm study across phases of its lifecycle. Thus, the applicability of CLV and customer equity models as tools to drive firm value across all firm lifecycle phases has yet been validated.

Using the customer equity model in Gupta et al. (2004), I conduct a within-firm case study of Netflix - a company that did report sufficient customer metrics between 2001 and 2011 to consistently estimate CLV - to see how Netflix's customer equity tracked its market capitalization under different lifecycle conditions.

Any evidence based on one firm can only be suggestive, but this case study offers the first reference point on when customer equity may link closely to a firm's market capitalization, and when it may not.

\footnotetext{
* Tel.: +44 2070008608 .

E-mail address: szhang@london.edu.
} 
Specifically, I value Netflix's customer equity each quarter over 10 years and examine its relationship to Netflix's market capitalization over the following three phases:

1) Initial growth. Netflix is a DVD rental business that started trading publicly in 2002 Q2. It did not realize a profit until 2003 Q2 and then slipped back and forth between profit and loss. How well did customer equity track market capitalization in this phase? Also, did customer equity track market capitalization better during periods of loss versus profit?

2) Expansion and maturity. From 2005 to 2008, Netflix steadily grew in customers. It also survived the Global Financial Crisis, which involved broad stock market declines from 2008 Q3 to 2008 Q4. How well did customer equity perform during this phase? When markets were crashing during the Global Financial Crisis, did investors rely on customer equity to value the firm?

3) Radical innovation. Netflix started online video streaming in 2007, offering a service that would replace and outgrow its original DVD rental business. How well did customer equity capture market capitalization in this period of radical innovation, when existing businesses are threatened to deliver renewed growth ${ }^{1}$ ?

\section{Model}

Following the literature, ${ }^{2}$ Netflix's customer equity is the sum of the CLVs of cohorts of customers. Consider at period 0 , if $n_{0}$ customers are acquired at a cost of $c_{0}$ each, then the CLV of this cohort 0 of customers can be expressed as:

$$
C L V_{0}=n_{0} \sum_{t=0}^{\infty} m_{t} \frac{r^{t}}{(1+i)^{t}}-n_{0} c_{0}
$$

- $n_{0}$ is number of customers acquired at time 0

- $m_{\mathrm{t}}$ is margin per customer at time $t$

- $r$ is the period retention rate

- $i$ is the period discount rate

- $t$ is time period

- $c_{0}$ is the cost per customer acquired at time 0

Similarly, the CLV at time 0 of a subsequent cohort acquired at time $k$ - if $n_{k}$ is the number of new customers acquired and $c_{k}$ is the cost of each new customer acquired at time $k$ - will be:

$$
C L V_{k}=\frac{n_{k}}{(1+i)^{k}} \sum_{t=k}^{\infty} m_{t-k} \frac{r^{t-k}}{(1+i)^{t-k}}-\frac{n_{k} c_{k}}{(1+i)^{k}}
$$

The value of the customer equity at time 0 is then the sum of the CLVs of all cohorts: ${ }^{3}$

$$
\text { Value }_{0}=\sum_{k=0}^{\infty}\left[C L V_{k}\right]=\sum_{k=0}^{\infty}\left[\frac{n_{k}}{(1+i)^{k}} \sum_{t=k}^{\infty} m_{t-k} \frac{r^{t-k}}{(1+i)^{t-k}}\right]-\sum_{k=0}^{\infty} \frac{n_{k} c_{k}}{(1+i)^{k}}
$$

The number of new customers in each period $n_{t}$ is modeled via the technological substitution model with parameters estimated using disclosed customer data. ${ }^{4}$ The technological substitution model describes cumulative customers' $N_{\mathrm{t}}$ at time $t$ as:

$$
N_{t}=\frac{\alpha}{1+\exp (-\beta-\gamma t)}
$$

\footnotetext{
${ }^{1}$ Radical innovations are products that both integrate a new technology and better satisfy customer needs. Such products yield renewed growth but can make existing products obsolete and often require a "willingness to cannabalize" (Chandy \& Tellis, 1998).

${ }^{2}$ I use the discrete model in Gupta and Lehmann (2005) and Gupta et al. (2004).

${ }^{3}$ This is the expression for the customer equity at time 0 . The customer equity at a future time $j$ will consist of two parts. The first part is the value of the cohorts acquired after time $j$ and the second part is the future value of retained customers from cohorts acquired from time 0 to time $j$ :

Value $_{j}=\sum_{k=j}^{\infty}\left[\frac{n_{k}}{(1+i)^{k-j}} \sum_{t=k}^{\infty} m_{t-k} \frac{r^{t-k}}{(1+i)^{t-k}}\right]-\sum_{k=j}^{\infty} \frac{n_{k} c_{k}}{(1+i)^{k-j}}+\sum_{k=0}^{j} n_{k} r^{j-k}\left[\sum_{t=k}^{\infty} m_{t-k} \frac{r^{t-k}}{(1+i)^{t-k}}\right]$

${ }^{4}$ Parameters in the technological substitution model are estimated from the full set of actualized customer data over the entire time period. In reality, an investor valuing the firm at any time $t$ would not know the actualized customer data after time $t$. This is not problematic with the assumption that investors can form noisy but unbiased expectations of the future. This estimation approach and assumption follow the existing literature.
} 
Table 1

\begin{tabular}{|c|c|c|c|c|c|}
\hline \multicolumn{6}{|l|}{ Source data summary } \\
\hline & Time Period & Periods & Average over period & Minimum & Maximum \\
\hline Number of customers ('000s) & $2001 \mathrm{Q} 1$ to $2011 \mathrm{Q} 4$ & 44 & 7449 & 303 (2001 Q1) & 25,269 (2011 Q3) \\
\hline Quarterly margin & $2001 \mathrm{Q} 2$ to $2011 \mathrm{Q} 4$ & 43 & $\$ 20.35$ & $\$ 12.95(2010 \mathrm{Q} 4)$ & $\$ 31.08$ (2004 Q3) \\
\hline Acquisition cost (per customer) & $2001 \mathrm{Q} 2$ to $2011 \mathrm{Q} 4$ & 43 & $\$ 31.43$ & $\$ 11.13(2010 \mathrm{Q} 4)$ & $\$ 47.46(2007 \mathrm{Q} 1)$ \\
\hline Retention rate (quarterly) & $2001 \mathrm{Q} 2$ to $2011 \mathrm{Q} 4$ & 43 & $85.40 \%$ & $78.4 \%(2002 \mathrm{Q} 1$ and $2002 \mathrm{Q3})$ & 88.6\% (2010 Q1, Q3, and Q4) \\
\hline WACC (quarterly) & $2002 \mathrm{Q} 3$ to $2011 \mathrm{Q} 4$ & 38 & $3.01 \%$ & $1.14 \%(2002 \mathrm{Q} 3)$ & $5.43 \%(2005 \mathrm{Q} 3)$ \\
\hline Market capitalization (mn) & 2002 Q3 to 2011 Q4 & 38 & $\$ 2805.23$ & $\$ 208.80(2002 \mathrm{Q} 4)$ & \$13026.92 (2011 Q2) \\
\hline
\end{tabular}

Technological substitution model parameter estimates (2001 Q1 to 2011 Q4)

\begin{tabular}{|c|c|c|c|c|c|}
\hline $\operatorname{Ln}(\alpha)$ & $\beta$ & $\gamma$ & $\mathrm{N}$ & R-squared & Root MSE \\
\hline $10.156^{* * *}$ & $-4.306^{* * *}$ & $0.133^{* * *}$ & 44 & .9864 & .1556 \\
\hline \multicolumn{6}{|c|}{ Recalibrated technological substitution model parameter estimates (2009 Q1 to 2011 Q4) } \\
\hline $\operatorname{Ln}(\alpha)$ & $\beta$ & $\gamma$ & $\mathrm{N}$ & R-squared & Root MSE \\
\hline $12.281^{* *}$ & $-6.529^{*}$ & $0.108^{* *}$ & 12 & .9710 & .0684 \\
\hline
\end{tabular}

${ }^{* * *} \mathrm{p}<.01{ }^{* *} \mathrm{p}<.05{ }^{*} \mathrm{p}<.10$. Estimation of technological substitution was done using non-linear least squares. Customer numbers were in thousands. The $\alpha$ parameter was estimated in logarithm for ease of computation and presentation. R-squared may not be a reliable fit statistic for non-linear least squares, so the root MSE would be a better fit measure (Srinivasan \& Mason, 1986).

Taking the derivative allows for the number of new customers at each period to be described as:

$$
n_{t}=\frac{\alpha \gamma \exp (-\beta-\gamma t)}{[1+\exp (-\beta-\gamma t)]^{2}}
$$

In accordance with Gupta et al. (2004), customer equity as modeled above would proxy for the market capitalization of Netflix. ${ }^{5}$

\section{Data and estimation}

Via Netflix's quarterly and annual SEC filings, ${ }^{6}$ I obtain the reported number of customers, customer acquisition cost, margin per customer, and customer retention rate for each quarter from 2001 Q2 to 2011 Q4 (number of customers are available for one quarter earlier from 2001 Q1). Data on customer retention or churn were no longer reported after 2011 Q4. Market capitalization values for Netflix are available after its IPO starting in 2002 Q3 and downloaded from Bloomberg. ${ }^{7}$ The discount rate $i$ used is the market WACC at any point in time for Netflix, downloaded from Bloomberg. ${ }^{8}$

Table 1 shows summary statistics and the estimated parameters from the technological substitution model.

\section{Valuation results and discussion}

Fig. 1a shows Netflix's customer equity values in comparison with market capitalizations on a quarterly basis. One can observe the correspondence of customer equity to market capitalization over the firm's lifecycle phases and conditions.

\subsection{Initial growth}

Netflix began sustained profitability after 2005 Q2, so I take the initial growth phase to run from 2002 Q3 to 2005 Q1.

Over the 11 quarters of this period, customer equity valued Netflix by an average of $\$ 666$ million above market capitalization, compared to an average overvaluation of $\$ 128$ million in the subsequent 11 quarters $(p<0.01) .{ }^{9}$ Furthermore, 5 out of the 11 quarters during the initial growth phase showed net loss. Over these periods of loss, customer equity was $\$ 828$ million too high on average, which was not statistically different from the $\$ 531$ million average overvaluation over the other 6 profitable quarters.

\footnotetext{
${ }^{5}$ Additional accounting adjustments to the customer equity may be performed before comparing to market capitalization as explained in Schulze, Skiera, and Wiesel (2012). These adjustments on net do not qualitatively impact the argument and results in the current study. Thus, I follow the original model of Gupta et al. (2004).

${ }^{6}$ Netflix SEC filings are available from ir.netflix.com. Last accessed: 31 July 2015.

7 The market capitalization is available as daily data via Bloomberg field name “CUR_MKT_CAP". Last accessed: 31 July 2015.

8 The WACC - Weighted Average Cost of Capital - is the market estimate of the discount rate to apply to the specific firm, after taking into account risk, debt, and taxes (Schulze et al., 2012). It is an average of the required rate of after-tax equity return and the required interest rate on debt for a firm. The WACC is available via Bloomberg field name "WACC". Last accessed: 31 July 2015.

${ }^{9}$ Many IPOs fail in the first few years (Demers \& Joos, 2007). However, the overvaluation would not be due to unaccounted risk of start-up failure, because this risk would be accounted for in the WACC discount rate.
} 


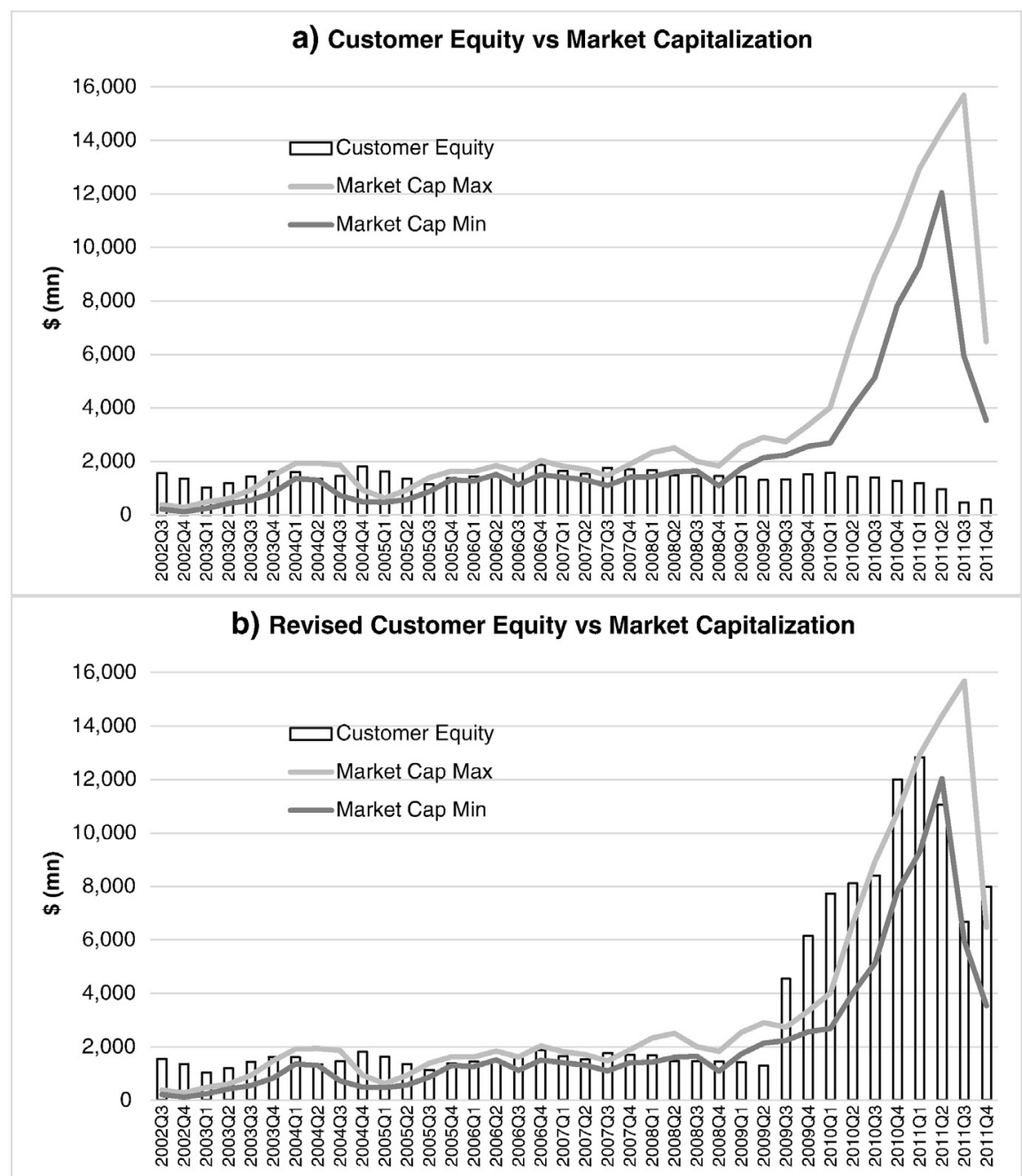

Fig. 1. Panel (a): Customer equity values versus market capitalization, where customer equity is based on the model of Gupta et al. (2004). Panel (b): Customer equity values versus market capitalization, where customer equity values incorporated recalibrated parameters after 2009 Q3.

Thus, customer equity does provide guidance on market capitalization in periods of negative profit consistent with periods of positive profit. However, the customer equity model somewhat overvalued Netflix in the initial growth phase overall regardless of profitability.

\subsection{Expansion and maturity}

I take 2005 Q2 to 2008 Q4 as the expansion and maturity phase of the original Netflix DVD business before online video streaming began to take off in 2009. Over the 15 quarters of this phase, customer equity tracked market capitalization remarkably well - valuing within range in 9 out of 15 quarters. Even more remarkably, the average customer equity values did not statistically differ from the market capitalizations over this period.

Furthermore, during the market crash of the Global Financial Crisis in 2008 Q3 and 2008 Q4, when the NASDAQ composite dropped 35\%, customer equity continued to track market capitalization for Netflix.

\subsection{Radical innovation}

The most striking feature of Fig. 1a is the dramatic divergence of customer equity values from market capitalizations starting in 2009. This period coincides with the emergence and take-over of video streaming as Netflix's business model, and points to the need to adjust the CLV customer equity model after a radical innovation to track market capitalization. 
Netflix introduced video streaming in 2007 as a free extra to DVD rental customers, and streaming usage became substantial over the course of 2009-2010. ${ }^{10}$ Streaming reached an inflection point in 2010 Q4, when customers streamed more hours of content than they watched on DVD (2010 Annual Report, p.1). In 2010 Q4, Netflix announced that streaming would be the business model of Netflix going forward, with CEO Reed Hastings stating to the press "We are now primarily a streaming video company delivering a wide selection of TV shows and films over the Internet" (Riley, 2010). Language also changed in the 2010 Annual Report: "Going forward, we expect we will be primarily a global streaming business, with the added feature of DVDs-by-mail in the US." (2010 Annual Report, p.1).

Replacing DVD rental with streaming was a radical innovation that required investors to revise and recalibrate estimations of Netflix's customer base. To capture investors' recalibration, Table 1 includes recalibrated estimates of the technological substitution model parameters based only on data after 2009 Q1, when streaming became substantial. These recalibrated model parameters are then used to produce revised valuations for Netflix from 2010 Q4 onwards, after the new business model became evident. Between 2009 Q3 and 2010 Q3, when the fate of streaming as the new business model was hanging in the balance, the revised valuations from recalibrated parameters are weighted with the old valuations using percentage of customers engaged in streaming, as per available data described in Footnote 10, to proxy for investor belief in the likelihood of the new streaming business model.

As can be seen in Fig. 1b, after the recalibration adjustment, customer equity substantially tracks market capitalization after 2009.

\section{Conclusion}

This study of Netflix demonstrates that customer equity can serve as a good guide to a firm's market capitalization during periods of stable expansion. Additionally, customer equity as a proxy for market capitalization is not impacted by volatility in profitability or a broad stock market crash. This supports the use of CLV and customer equity as marketing management metrics to increase firm value under many lifecycle conditions.

However, Gupta et al. (2004) also had in mind the applicability of customer equity to value fast growing firms that rely on innovation, such as internet firms. For firms that are growing via radical innovation, this study shows that CLV-based customer equity models require timely recalibrations as radical innovations take off. This suggests a condition on the applicability of recent CLV models that forecast customer behavior based on past behavior, for example Fader, Hardie, and Shang (2010) and Zhang, Bradlow, and Small (2015). Parameters of such CLV models should be re-estimated after instances of radical innovation.

\section{Acknowledgement}

The author thanks editor Joel Huber and anonymous reviewers for helpful feedback.

\section{References}

Chandy, R., \& Tellis, G. (1998). Organizing for radical product innovation: The overlooked role of willingness to cannibalize. Journal of Marketing Research, $35,474-487$. Demers, E., \& Joos, P. (2007). IPO failure risk. Journal of Accounting Research, 45(2), 333-371.

Fader, P. S. (2012). Customer Centricity: Focus on the Right Customers for Strategic Advantage (2nd ed.). Wharton Digital Press.

Fader, P. S., Hardie, B. G. S., \& Shang, J. (2010). Customer-base analysis in a discrete-time noncontractual setting. Marketing Science, 29(6), 1086-1108.

Gupta, S., \& Lehmann, D. (2005). Managing Customers as Investments. FT Press.

Gupta, S., Lehmann, D., \& Stuart, J. (2004). Valuing customers. Journal of Marketing Research, 41(1), 7-18.

Riley, C. (2010, 22 Novemberr). “Netflix raises prices, offers streaming-only option”. CNN Money (Last retrieved on 1 February 2016 from http://money.cnn.com).

Schulze, C., Skiera, B., \& Wiesel, T. (2012). Linking customer and financial metrics to shareholder value: The leverage effect in customer-based valuation. Journal of Marketing, 76, 17-32.

Srinivasan, V., \& Mason, C. (1986). Nonlinear least squares estimation of new product diffusion models. Marketing Science, 5(2), 169-178.

Zhang, Y., Bradlow, E. T., \& Small, D. S. (2015). Predicting customer value using clumpiness: From RFM to RFMC. Marketing Science, 34(2), 195-208.

\footnotetext{
${ }^{10}$ Netflix reported customer engagement with streaming at 40\% in 2009 Q3, 48\% in 2009 Q4, 55\% in 2010 Q1, 61\% in 2010 Q2, and 66\% in 2010 Q3. Netflix defines customer engagement as percent of customers who streamed at least 15 min of video in the quarter. The metric was only reported from 2009 Q3 to 2010 Q3.
} 